\title{
Overt and Null Subject Pronouns in Jordanian Arabic
}

\author{
Islam M. Al-Momani \\ Department of English Language and Literature, Princess Alia University College, Al-Balqa' Applied University, Jordan \\ E-mail: almomani_islam@yahoo.com
}

Doi:10.7575/aiac.alls.v.6n.4p.1

URL: http://dx.doi.org/10.7575/aiac.alls.v.6n.4p.1
Received: 25/02/2015

Accepted: 02/05/2015

\begin{abstract}
The paper aims at examining the role that morphology plays in allowing and/or motivating sentences in Jordanian Arabic (hereafter JA) to be formed with or without subject pronouns. It also aims at giving a comprehensive and descriptive presentation of the distribution of overt and null subject pronouns in JA, and tries to determine to what extent there is optionality in its system.
\end{abstract}

Keywords: null subject pronouns, overt subjects, pro-drop languages, verbal inflectional morphology

\section{Introduction}

The idea that some languages allows verbal arguments to remain unexpressed has gained a great deal of attention in recent years from linguists working within generative grammar. The possibility of not overtly expressing a verbal argument is connected some way to inflectional morphology of the language, i.e., the inflectional markers attached to the verb determines the person number and gender features of the intended subject, and hence, an overt subject is referentially redundant and therefore, can be omitted.

By assumption, all languages generate a subject position in the syntactic representation of sentences, the [SPEC, IP] position. But why languages like English for instance always have an overt lexical item in this position while other languages like Arabic and Italian may have an empty category in that syntactic position? This difference could be justified according to the different setting of parameters of Universal Grammar (UG). Languages that allow unexpressed subjects are referred to as pro-drop languages, and have positive setting, while languages that require the subject to be always expressed and the position to be filled with a lexical material are referred to as non-pro-drop languages, and have negative setting.

The option to choose between the use or the non-use of an overt subject NP is considered as a kind of synchronic variation which gives the speaker alternative ways to express the same meaning and thus, speakers choose options available to them as far as the informational content, the meaning is preserved. Labov (1994:568), while reviewing a number of studies related to the speakers' choice of the two forms, has stated that "...... in the stream of speech, one variant or the other is chosen without regard to the maximization of information. On the contrary, the major effects that determine such choices are mechanical: phonetic conditioning and simple repetition of preceding structure". He has also stated, while reviewing a research done by Cameroon (1992) on the relationship between the loss of particular morphological distinctions in Spanish verbal paradigms and the frequency of overt pronoun use, that "..... whatever processes are operating to increase the pronoun use in Latin American dialects, they cannot represent a response to speakers' perceived need to convey information, by providing pronouns in the particular utterances where verbal inflections are missing" (576).

In languages that have rich inflectional morphology, it is that morphology which identifies the null subject in the event that is licensed and thus makes it possible to have such null subjects. Proposals and researches for the formal representation of overt and null subject pronouns were done under the Principles and Parameters theoretical syntax framework. Following the schema set out in the "X-Bar theory", it has been argued in the Phrase Structure, the Government and Binding, and the Minimalist Program within the Principles and Parameters model that all natural languages are binary branching. The structure of sentences and phrases, accordingly, may be represented as in the tree diagram shown below:

1.

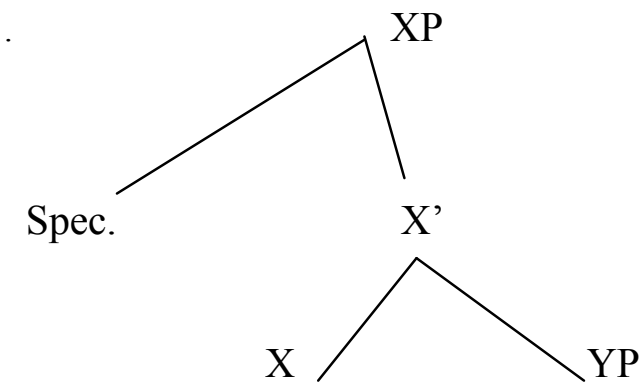


Here, $(\mathrm{X})$ is the head of the phrase which could be either a lexical head or functional head combines with YP, (its complement) to form an intermediate level of structure referred to as $\mathrm{X}$-bar, $\left(\mathrm{X}^{\prime}\right)$. The $\mathrm{X}^{\prime}$ in turns combines with its Spec. (Specifier) to form the maximal projection of the head X, notated as XP.

The GB model adopted the schema shown above and accordingly the structural representation is represented as shown below:

2.

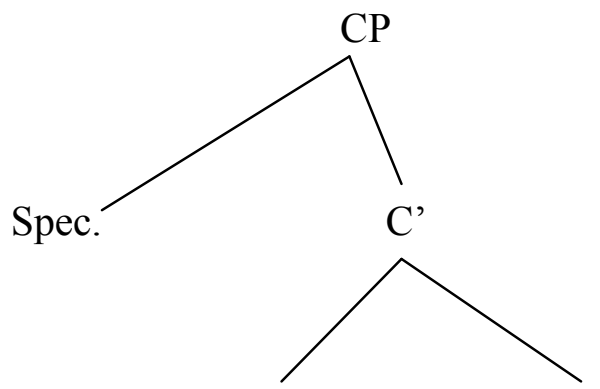

$\mathrm{C}$

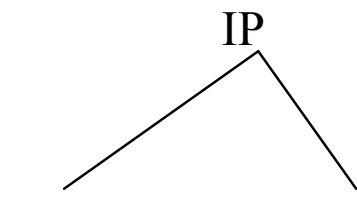

SPEC.

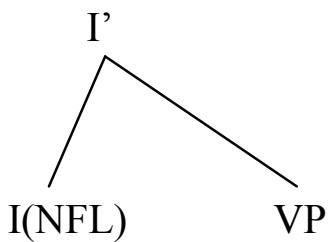

The I(NFL) node of (I') which contains both tense and agreement features is the head of the inflectional phrase represented as IP. The subject of the sentence served as the Specifier of the IP. The Complementizer represented as (C), the head of the higher structure (CP), combines with the IP to form an intermediate level of structure referred to as C'. This structure in turns combines with its Spec to form that maximal projection. To this higher layer of structure, the Wh-phrases of interrogatives move in languages. Pollock (1989) has introduced a further refinement of the functional head projection known as the "Split INFL hypothesis". The proposal disintegrated the IP into TP (Tense Phrase) and AGRP (Agreement Phrase) as in the following:

3.
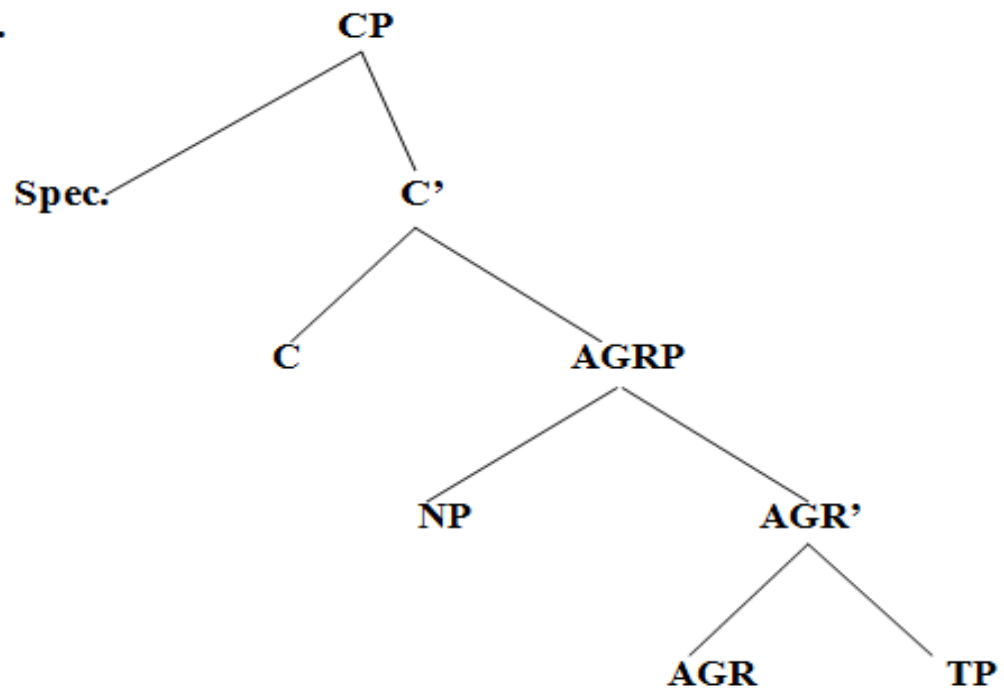

SPEC

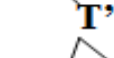

Tense 
Within the (GB) version of the Principles and Parameters framework in the 80s, for Empty Categories, (ECs) to be licit have to be "properly governed". According to Rizzi (1982), empty categories in Italian language are licit because they are properly governed by virtue of rich verbal inflections. Other analyses of null subjects were proposed by Chomsky (1982), and Hyams $(1986,1989)$. They have asserted a connection between rich verbal inflections and the possibility of null subjects. Borer $(1986,1989)$, while discussing Hebrew, has presented data to demonstrate that the possibility of null subjects is linked to the richness of agreement features of the predicate. Jordanian Arabic, like other dialects of Arabic, has fairly rich verbal inflectional morphology that specifies the nominal features of person, number and gender of the null subject as unambiguously as an overt subject would. As assumed correctly by Benmamoun (1994), Eid (1993), Mohammad (1988), Farghaly (1982), and Jelinek (1983, and 2002), while discussing various dialects of Arabic, that null subjects are possible only when the predicate has person subject marking which is argued to be necessary to recover the absence of the subject from the sentence.

Kenstowicz (1989) has studied the null subject in a Levantine dialect and the Bani-Hassan dialect (two dialects of Arabic) within the GB framework. The study has primarily focused on the relation between postverbal subjects and the lack of that-trace effects. He has suggested that the null subject parameter should be set independently for different clause types in the two dialects. As the Levantine dialect, shows a positive setting for the null subject parameter only in matrix clauses, the Bani-Hassan dialect shows a positive setting for the parameter in both matrix clauses and embedded complement clauses.

In the Minimalist Program which is a more recent proposal within the Principles and Parameters framework, Chomsky $(1993,1995)$ has assumed that there is no more requirements for all the sentences to generate the syntactic position of the sentence subject, [Spec, IP]. Therefore, there is no longer any need to hypothesize the empty category, 'pro' to fill the position of the subject. The verb could occur in initial position and satisfy the EPP (Extended Projection Principle) of Chomsky (1982), in which he has assumed that every sentence must have a subject, by checking the D features of the EPP by virtue of the fact that inflections on the verb are lexical and have separate entities in the lexicon.

Thus, this proposal continues to assume the possibility of having a connection between null subjects and rich inflectional morphology, i.e., the morphological recovery at the sentence level plays a crucial role in making null subjects licit.

\section{Objectives and Methodology}

In this paper, the researcher is concerned with the analysis of null subject pronouns in JA, and thus follows the descriptive-analytical approach. The data used here is an amalgamation of genuine sentences uttered by native speakers of JA. Casual speech is tape-recorded for the subjects talking freely about different topics of their choices for different periods of time.

The study aims at answering the following questions:

1. Are overt subject pronouns in JA optional or obligatory?

2. When and why could overt subject pronouns be omitted?

3. How could omitted subject pronouns be interpreted?

4. What governs the omission of subject pronouns?

5. When are overt subject pronouns obligatory?

The following symbols are used to represent certain Arabic sounds that don't match IPA symbols.

/ș/ voiceless alveolar emphatic fricative

$/ \mathrm{h} /$ voiceless pharyngeal fricative

c\% voiced pharyngeal fricative

/q/ voiceless uvular stop

$/ \dot{\mathrm{g}} /$ voiced velar fricative

\section{Discussion}

\subsection{Null Subjects Pronouns in JA}

In order to prove that the role of morphology in JA is very crucial in allowing sentences to be formed with or without an overt subject, consider the JA sentences and their English counterparts in (4).

3.

JA

a. ?ana/Ø bal'ab korah kul-yom

I-1S/Ø play-1S football every day

I play football every day.

b. ?inta/ Ø ?ibtil ab korah kul-yom

you-2MS/Ø play-2MS football every day

You play football every day.
English

I play football every day.

You play football every day. 


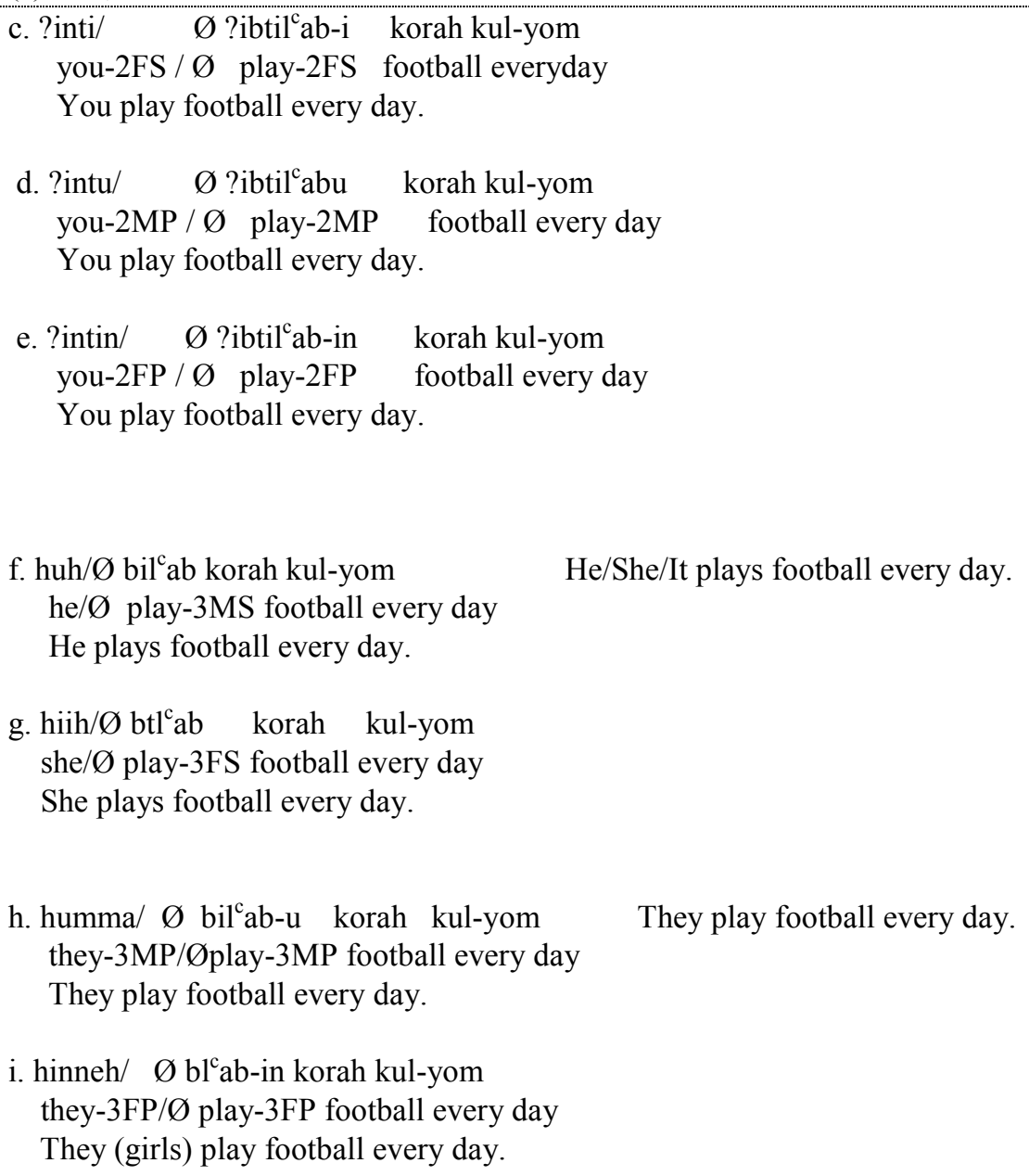

In JA, the subject of a finite clause can be dropped, whereas in languages like English the subject cannot be dropped. In generative grammar, the empty category in pro drop languages which is taken to be "pro" corresponds to an overt pronoun in non-pro drop languages. Sentences in (4) show that JA has fairly rich verbal inflectional morphology that recovers the absence of the verbal argument and specifies the nominal features of person, number and gender of that subject as clearly as an overt subject pronoun would. In sentence (4a), for instance, the morphological inflectional marker ' $b a$ ' attached as a prefix to the verb ' $1{ }^{c} a b$ ' is a first person singular marker that allows the subject pronoun '?ana', (I) to be omitted. In (4g), the inflectional marker 'bt' is third person singular feminine that makes the presence of the subject pronoun 'hiih', (she) optional. In (4h), two inflectional markers are attached to the verb ' $\mathrm{l}^{\mathrm{c}} \mathrm{ab}$ ', one is the prefix 'bi' indicating the person and gender; whereas, the inflectional suffix ' $u$ ' indicates the number. It is clear that the JA verbal inflectional paradigm is richer than the verbal inflectional paradigm in English. In JA, there are nine verb forms corresponding to the nine independent pronouns, and therefore, the verbal morphology is as unambiguous as the independent pronouns in terms of identifying the nominal features of person, number, and gender (the phi-features) of a referent. The morphological realization of agreement in the English paradigm is less rich because it has only two forms, one serving the third person singular, and the other for all other phi-feature combinations. English, accordingly, exhibits only two forms in the verbal paradigm corresponding to nine independent nominative pronouns in JA.

Based on the aforementioned examples, the recovery of unexpressed subject pronouns in JA is possible only when the predicate has person subject marking. It is considered as a pronominal marking in the predicate and argued to be necessary in order for the subject pronoun to be omitted without violating the EPP. This principle can be satisfied in JA by means of null forms which only occur in the subject position.

\subsection{The Types of Null Subject in JA}

Before discussing the types of null subject pronouns, their nonoccurrence and their recovery through pronominal inflections in the subject position in JA sentences, it is worth giving a sketch of the word order of JA in order to decide whether the subject is restricted to one and only one fixed position or not.

JA, like Modern Standard Arabic and other Arabic dialects, exhibits different word order and accordingly different subject positions. The subject may occur after the verb in VSO order as in (5), and before the verb in SVO order as in (6).

\footnotetext{
4. ?akal comar ?ituffahah

ate ${ }^{\mathrm{c}}$ omar apple

Omar ate an apple.
} 
5. 'omar ?akal ?ituffaћah

'omar ate apple

Omar ate an apple.

In JA, agreement asymmetries is very clear, whereby, in VSO order, the subject partially agrees with the verb as seen in (7), it fully agrees with the verb in SVO order as in (8).

6. a. naamat 1-bint

slept-3SF the-girl

The girl slept.

b. naamat 1-banaat

slept-3SF the-girls

The girls slept.

7. a. 1-bint naamat

the-girl slept-3SF

The girl slept.

b. 1-banaat naam-in

the-girls slept-3PF

The girls slept.

In (7b), the subject NP 'l-banaat', (the girls) agrees with the verb 'namat' according to person and gender but not number. Thus, agreement is partial. In SVO order as in (8b), the subject NP '1-banaat' agrees fully with the verb 'namin' according to the nominal features of person, number and gender.

As far as the subject of a finite clause is concerned, a distinction between JA and Modern Standard Arabic regarding the morphological realization of "Case" seems important. In Modern Standard Arabic, the subject is assigned Nominative case generally realized overtly as the noun suffix ' $-u$ '. Consider the following sentence.

8. naama r-rajul-u

slept the-man-nom

The man slept.

Sentence (9) shows that the Nominative case is overtly realized by the suffix '-u' attached to the lexical NP, 'r-rajul'. In JA, the overt case marking on lexical NPs disappeared regardless of the word order used as in (10).

9. a. naam l-walad slept the-boy

The boy slept.

b. 1-walad naam

the-boy slept

The boy slept.

Only in pronouns, the overt case marking can be seen when used as subjects of finite clauses. Consider the examples in (11).

10. a. huu bu-drus

he 3PSM-studying

$\mathrm{He}$ is studying.

b. hii btu-drus

she 3PSF-studying

She is studying.

c. hummo bu-drus-u

they 3P-studying-M.Pl.

They are studying.

d. hinne bu-drus-in

they 3P-studying-F.Pl.

They (girls) are studying.

The examples in (11) follow the SV order which is more popular in JA than the VS order particularly when the subject of the sentence is a pronoun. 
Null subjects are allowed in many languages despite the possibility of their recovery through pronominal inflections. In JA, null subjects can be classified into three different types: (1) referential argumental null subjects, (2) non-referential argumental null subjects, and (3) non-referential non-argumental null subjects.

\subsubsection{Referential Argumental Null Subjects}

Referential null subjects may be determined by a process called recoverability (Taraldsen 1978) or identification (Jaeggli 1982). That is, the pronoun in the subject position may be omitted only if its content can be recovered morphosyntactically. Consider the contrast in (12) and (13).

11. JA

a. 'omar qaal ?innu Ø be-naam bakkir kul-yom

comar said that $\varnothing 3$ SM-sleep early every day

Omar said that he sleeps early every day.

b. hind qaalat ?innu Ø bet-naam bakkir kul-yom

hind said that $\varnothing 3 \mathrm{SF}$-sleeps early every day

Hind said that she sleeps early every day.

c. 1-wlaad qaal-u ?innu Ø be-naam-u bakkir kul-yom

the-boys said-P1.M that $\varnothing$ 3.P-sleep-Pl.M early every day

The boys said that they sleep early every day.

d. 1-banaat qaal-in ?innu Ø be-naam-in bakkir kul-yom the-girls said-P1.F that $\varnothing 3$ P-sleep-Pl.F early every day

The girls said that they sleep early every day.

12. English

*a. Bill said that Ø slept early yesterday.

*b. Mary said that $\varnothing$ slept early yesterday.

*c. The boys said that $\varnothing$ slept early yesterday.

*d. The girls said that $\varnothing$ slept early yesterday.

As can be seen in (12), JA allows the omission of the subject of an embedded finite clause because it can be recovered by the nominal inflections attached to the verb. In sentence (12a), for instance, the presence of the morphological inflectional marker 'be', which a third person singular masculine prefix attached to the verb 'naam' allows the subject pronoun of the embedded clause to be omitted. The verbal morphology found in JA can determine the content of the missing subject, thus making it redundant and recoverable. The English sentences in (13) are ungrammatical because the absence of the subject in the embedded finite clauses. The system of the verbal morphology in English is not rich and cannot recover the content of the missing subject and accordingly the possibility of dropping the subject from a tensed clause can never exist.

The null subject parameter predicts that only the arguments with which the verb agrees can be dropped and encoded in term of EC, and thus there should exist an elaborated system of verbal agreement, i.e., a rich inflectional morphology that can recover the absence of the subject.

\subsubsection{Non-Referential Argumental Null Subjects in JA}

Consider the contrast in (14) and (15).

13. ?ibt-ishti barra

Ø3FS-rain outside

(It) is raining outside.

14. * Ø is raining outside.

Sentence (14) indicates the possibility of dropping the non-referential argumental subject in JA because it can be recovered through the third personal feminine prefix, (?ibt) attached to the verb "ishti". (15) is ungrammatical because the impersonal pronoun "it" is dropped and cannot be recovered.

\subsubsection{Non-referential Non-Argumental Null Subjects in JA}

Languages that allow the occurrence of referential null subjects necessitate the occurrence of non-referential nonargumental null subjects, expletive (non-thematic) null subjects but not vice versa. According to Rizzi (1982, and 1986), Jaeggli and Safir (1989a), Abraham (1993), and Y. Huang (1994), the properties of expletive null subjects are a 
subset of the properties of referential null subjects. Consider the JA sentences in (16) and their English counterparts in (17)

15. a. Ø ka?annu l-walad lissat-u șah-i seem-that the-boy still-3PSM awake-3PSM

It seems that the boy is still awake.

b. Ø ka?annu 1-binit lissat-a șah-ya seem-that the-girl still-3PSF awake-3PSF

It seems that the girl is still awake.

c. Ø ka?annu 1-wlaad lissat-hum șah-yiin seem-that the-boys still-3P.PI.M awake-3P.PI.M It seems that the boys are still awake.

d. Ø ka?annu 1-banaat lissat-hin șahy-at seem-that the-girls still-3P.P1.F awake-3P.Pl.F It seems that the girls is still awake.

16. a. ${ }^{*} \varnothing$ seems that the boy is awake.

b. ${ }^{*}$ seems that the girl is awake.

c. ${ }^{*} \varnothing$ seems that the boys are awake.

d. ${ }^{*} \varnothing$ seems that the girls are awake.

All the sentences in (16) are grammatical and hence JA allows expletive null subjects, whereas their English counterparts in (17) are ungrammatical because the expletive pronoun is missing.

JA like other pro-drop languages allows null subjects to co-occur with two distinctive properties, namely: (i) the possibility of having free subject inversion, and (ii) the possibility of having complement subject extraction. These two properties, according to Rizzi (1982) are considered very important, and linked as a function of the positive value of the null subject parameter. He has also formalized an obvious connection between rich verbal inflection and null subjects in Italian by proposing that the inflectional node, INFL has the feature [+pronominal] and is thus a proper governor of the subject empty category. The fact that the subject empty category is properly governed makes it possible for the subject to occur in postverbal position. Below are examples in JA of both free subject inversion and complement subject extraction.

17. bel'ab ${ }^{\mathrm{c}}$ omar kurah play ${ }^{\mathrm{c}}$ omar football

Omar plays football.

18. ?aiyya walad betfakkir innu katab Ø l-risaleh which boy think (you) that wrote the-letter Which boy do you think wrote the letter?

Sentences (18) and (19) show the possibility of having null subjects in JA comes together with the possibility of having free subject inversion and the possibility of having complement subject extraction.

\subsection{The Verb Morphology in JA}

The verb morphology in JA is crucial to the interpretation of null overt pronouns in the subject position. In JA, the context and the semantic features of overt pronouns become less important for the correct identification of the subject in a sentence because one relies on the verb morphology for its identification, and thus, Null pronouns are preferred over overt pronouns because they add no additional advantage in the context.

Verbs in JA are distinguished morphologically from other categories because not only they carry nominal inflections that recover the missing subject pronouns but also inflections that reflect tense and aspect. Below a description of JA verbs with information about both: pronominal inflections in imperfective and perfective modes. The imperfective and the perfective modes can be exemplified as shown in (20) and (21) respectively.

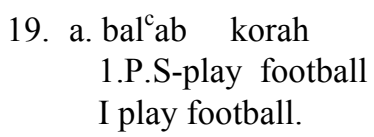



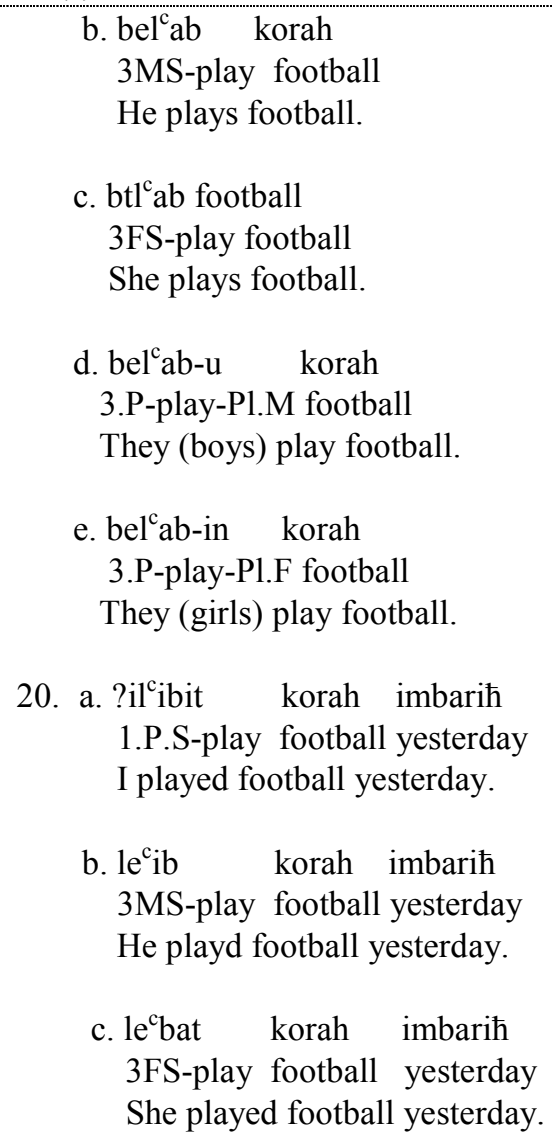
d. le $e^{\mathrm{c} b-\mathrm{u}} \quad$ korah imbarih 3.P-play-P1.M football yesterday They (boys) played football yesterday.
e. le $e^{c} b$-in korah imbareh 3.P-play-Pl.F football yesterday They (girls) played football yesterday.

Sentences in (20), and (21) show that the subjects is missing but can be recovered by the different verb forms that identify the nominal features of person, number and gender of the missing subject. Thus, the pronominal inflection plays the same semantic role that the pronoun plays in JA. Moreover, all the verbs in (20) and (21) show tense/aspect inflections, for instance, in $(20 \mathrm{~b})$ the presence of the morphological inflectional marker 'be', which a third person singular masculine prefix attached to the verb ' 1 ' ab' shows not only the phi-features of the omitted subject pronoun of the sentence, but also the present tense form of the verb. Whereas, in $(21 \mathrm{~b})$, the pronominal inflectional marker, 'le' shows the past tense form of the verb 'le $e^{c} i b$ '. Thus, the overt pronoun in the subject position is not crucial because its semantic features such as person, number and gender are totally superfluous because this information is already encoded in the verb. In this sense, overt pronouns do not help in the identification of the subject. The overt pronoun in the subject position in JA like other pro-drop languages adds no new information and hence, the use overt pronouns will not serve their specialized function.

The extensive use of null pronouns in the subject position in JA which is, like other dialects of Arabic, a null subject language could happen for two reasons. First, less articulatory effort is involved in the production of sentences containing null overt pronouns. Second, the null pronouns may have some stylistic value related to the expression of certain social attitudes.

The distinction between null and overt subject pronouns in JA can be explained in terms of contrast and emphasis. The contrastive function of the overt pronoun is the one which is most often cited by the native speaker to offer an explanation of the occurrence of overt subject pronouns. An example of an obligatory contrastive subject pronoun in JA is as given below.

21. Speaker A: weinak ya zalameh, min shahir $\varnothing$ badawwir ${ }^{c}$ a-leik.

Where are you man, from month I looking for-you

Where are you man, I have been looking since last month.

Speaker B: ana halla ?idreet innak bedawwir ${ }^{\mathrm{c}}$ a-lyya

I just know that (you) looking for-me

I have just known that you are looking for me. 
The overt pronoun 'ana' can be considered as an obligatory element in terms of the notion of contrast. Thus, in JA, the contrast is expressed by means of the presence of the pronoun.

The overt pronoun in the subject position can be categorized as an emphatic subject pronoun, i.e., the pronominal subject is used when one wants to highlight the role of the subject. Consider the following sentence:

22. Inta betgush be-1-?imtihan ya ${ }^{c}$ omar

You cheat in-the-examination, ${ }^{\text {o }}$ omar

You would cheat in the examination, Omar.

In (23), the speaker expresses his surprise that Omar whom he trusts very much would cheat in the examination. Like other null subject languages, the 'emphatic' function is used in JA to offer an explanation of the occurrence of overt pronouns in the subject position. The pronoun generally receives phonetic stress which, elsewhere, could be paraphrased by all native speakers as 'pro'.

Accordingly, the pronominal subject in JA is required to underline its importance, and may be used in circumstances where it is felt by a native speaker that the expression of the subject by means of verbal pronominal inflection is not enough in a certain action. Therefore, the presence of overt pronouns is considered as a kind of acknowledgement of the focused nature of that pronoun in subject position where it is most frequently omitted.

Thus, the presence and the absence of pronouns in pro-drop languages might be considered as an example of free variation with no significant consequences for the meaning of the sentence; besides, if the pronoun can be omitted, its presence nearly always has an emphatic or contrastive value.

\section{Conclusion}

The null subject pronoun in JA has a substantial advantage over the overt pronoun. The richer morphology of JA makes the verbal morphology, i.e., the nominal features of person, number, and gender crucial to the interpretation of the null subject pronouns. The occurrence of null subject pronouns in JA is determined by recoverability and identification, and thus both the context and the semantic features of the overt pronoun becomes less important as cues for the correct identification of the subject. Null subject pronouns in JA are preferred over overt subject pronouns because native speakers rely heavily on the verbal morphology, and overt subject pronouns offer no additional advantage in this point of view.

\section{References}

Abraham, W. (1993). Null subjects in the history of German: from IP to CP. Lingua, 89, 117-142. http://dx.doi.org/10.1016/0024-3841(93)90050-7

Benmamoun, A. (1994). The Conditions on pro and the ECP. The Proceedings of the Thirteen West Coast Conference on Formal Linguistics. Eds. Raul Aranovich, et al. Stanford: Center of the Study of Language and Information, 173188.

Borer, H. (1986). I-Subject. Linguistic Inquiry. 17(3), 375-416.

Borer, H. (1989). Anaphoric AGR. The Null Subject Parameter. Eds. Osvaldo A. Jaeggli and Kenneth J.Safir. Dordrecht: Kluwer Academy, 69-110. http://dx.doi.org/10.1007/978-94-009-2540-3_3

Cameroon, R. (1992). Pronominal and null subject variation in Spanish: Constraints, dialects and functional compensation. Unpublished doctoral dissertation. University of Pennsylvania.

Chomsky, N. (1982). Some Concepts and Consequences of the Theory of Government and Binding. Linguistic Inquiry Monograph 6. Cambridge: MIT Press.

Chomsky, N. (1993). A minimalist program for linguistic theory. In the View from Building 20, Kenneth Hale and Samuel Keyser (eds.), 1-52. Cambridge, MA: MIT Press.

Chomsky, N. (1995). The Minimalist Program. Cambridge, MA: MIT Press.

Eid, M. (1993). Negation and Predicate Heads in Arabic. Principles and Predication: The Analysis of Natural Language. Paper in honor of Gerald Sanders. Eds. Mushira Eid and Gregory Iverson. Current Issues in Linguistic Theory. Amsterdam and Philadelphia: John Benjamins, 98, 135-152.

Farghaly, A. (1982). Subject pronoun deletion rule in Egyptian Arabic. Discourse Analysis: Theory and Application Proceedings of the Second National Symposium on Linguistics and English Language Teaching. Eds. S. Gamal and R. Bower. Cairo: Center for Developing English Language Teaching, Ain Shams University, 60-69.

Huang, Y. (1994). The Syntax and Pragmatics of Anaphora. Cambridge: Cambridge University Press. http://dx.doi.org/10.1017/CBO9780511554292

Hyams, N. (1986). Language Acquisition and the Theory of Parameters. Dordrecht: D. Reidel. http://dx.doi.org/10.1007/978-94-009-4638-5

Hyams, N. (1989). The null subject parameter in language acquisition. In The Null Subject Parameter, Osvaldo A. Jaeggli and Kenneth J. Safir (eds.), 215-238. Dordrecht: Kluwer. http://dx.doi.org/10.1007/978-94-009-2540-3_7

Jaeggl, O. (1982). Topics in Romance Syntax. Dordrecht: Kluwer. 
Jaeggli, 0. and Safir, K. (1989a). The null subject parameter and parametric theory. The Null Subject Parameter. Eds. Osvaldo A. Jaeggli and Kenneth J. Safir. Dordrecht: Kluwer Academic, 1-44.

Jelinek, E. (1983). Person-subject marking in AUX in Egyptian Arabic. Linguistic Categories: Auxiliaries and related puzzles. Eds. Frank Heny and B. Richards. Dordrecht: D. Reidel Publishing Company, One: 21-46. http://dx.doi.org/10.1007/978-94-009-6989-6_2

Jelinek, E. (2002). Agreement, Clitics and Focus in Egyptian Arabic. Themes in Arabic and Hebrew Syntax. Eds. Jamal Ouhalla and Ur Shlonsky. Dordrecht: Kluwer Academic, 71-105. http://dx.doi.org/10.1007/978-94-010-0351-3_3

Kenstowicz, M. (1989). The null subject parameter in modern Arabic dialects. The Null Subject Parameter. (Eds.) Osvaldo A. Jaeggli and Kenneth J. Safir. Dordrecht: Kluwer Academic, 263-276. http://dx.doi.org/10.1007/978-94-0092540-3 9

Labov, W. (1994). Principles of Linguistic Change: Internal Factors. Oxford: Blackwell.

Mohammad, M. A. (1988). Nominative Case, I-Subjects, and Subject-Verb Agreement. CLS. Ed. Diane Brentari et al. Chicago: Chicago Linguistic Society, 223-235.

Pollock, J. (1989). Verb movement, UG and the structure of IP. Linguistic Inquiry, 20, 365-424.

Rizzi, L.(1982). Issues in Italian Syntax. Dordrecht: Foris. http://dx.doi.org/10.1515/9783110883718

Rizzi, L. (1986). Null Subject in Italian and the Theory of pro. Linguistic Inquiry, 17(3), 501-557.

Taraldsen, T. (1978). On the NIC, Vacuous Application and the That Trace Filter. Bloomington: Indiana University Linguistics Club. 